\title{
Effect of season on LH secretion in ovariectomized Australian cashmere does
}

\author{
Henniawati $^{1}$, B. J. Restall ${ }^{1}$ and R. J. Scaramuzzi ${ }^{2 *}$ \\ ${ }^{1}$ Wollongbar Agricultural Institute, NSW Agriculture, Wollongbar, NSW 2477, Australia; and \\ ${ }^{2}$ CSIRO, Division of Animal Production, Prospect, NSW 2148, Australia
}

\begin{abstract}
An experiment was conducted to define the seasonal changes in $\mathrm{LH}$ secretion in ovariectomized does with oestrogen implants and the effect of immunization against melatonin. Fifteen mature Australian cashmere goats were ovariectomized and given either no further treatment or one or two implants containing oestradiol; another similar group of 15 does were immunized against melatonin before ovariectomy and oestrogen treatment. LH concentrations and livemasses were recorded every week for 2 years. Livemasses of both groups showed a distinct seasonal pattern with a summer maximum and a winter minimum irrespective of treatment. LH concentrations also showed distinct seasonal patterns with a significant interaction between the number of implants and the time of the year. In the nonimmunized does, the presence of a constant low dose of oestrogen (one implant) resulted in low concentrations of LH except from May to August, the normal period of spontaneous ovulatory activity in intact does. In contrast, nonimmunized does receiving a high dose of oestrogen (two implants) showed a rise in LH concentrations in February, and concentrations remained high until August. Immunization against melatonin abolished this differential LH secretory pattern, and both doses of oestrogen were associated with a short period of high LH concentration between May and September. These results indicate that a negative feedback effect of oestrogen results in low LH secretion for most of the year and that hypothalamic sensitivity to LH decreases for only a short period between May and August. It is suggested that the early increase in LH secretion in does with two oestrogen implants is due to a positive oestrogen feedback mechanism that may depend on a photoperiodic signal for activation.
\end{abstract}

\section{Introduction}

The annual reproductive cycle in Australian goats is characterized by a relatively short period of spontaneous ovulation, preceded by a sensitive anovulatory period in which reproductive activity can be readily induced, and followed by an insensitive, or quiescent, anovulatory period (Restall, 1992). Mating occurs readily in the period preceding spontaneous ovulation in response to a marked male effect (Chemineau, 1983; Restall, 1988). The precise endocrinological control of this annual rhythm in goats has not been described, but is presumed to be similar to that of sheep and to involve control of the gonadotrophic system by an interaction between photoperiod and circulating steroid hormone concentrations (Pelletier and Ortavant, 1975; Legan and Karsch, 1979) and a transduction of photoperiodic information to the hypothalamic-pituitary axis by melatonin (sheep: Karsch et al., 1984; Arendt, 1986; goat: Chemineau et al., 1988a; Maeda et al., 1988). Behavioural, environmental and pheromonal

*Present address: Department of Veterinary Basic Sciences, Royal Veterinary College, University of London, Royal College Street, London NWI OTU, UK. Revised manuscript received 22 August 1994. factors affect the expression of seasonal reproductive activity in sheep and goats (Martin and Thomas, 1990; Walkden-Brown et al., 1993).

This report describes seasonal changes in LH secretion in ovariectomized does with oestrogen implants, the effect of immunization against melatonin on these animals and discusses the control of the seasonal reproductive rhythm in goats.

\section{Materials and Methods}

Location and animals

The experiment was carried out at the Pearces Creek substation of the Wollongbar Agricultural Institute $\left(28^{\circ} 48^{\prime} \mathrm{S}\right.$, $153^{\circ} 23^{\prime} \mathrm{E}$ ) using the domesticated offspring of cashmere animals bred from captured feral goats. The location, the general characteristics of the experimental animals and their management have been described elsewhere (Restall and Pattie, 1989). Animals were ovariectomized under general anaesthesia using standard surgical procedures (Hecker, 1974). 


\section{Experimental design}

Thirty, 19 month old, Australian cashmere does were randomly assigned to two groups: group 1: 15 does ovariectomized in June 1987, and group 2: 15 does immunized against melatonin in May, June and July 1987, and ovariectomized in November 1987.

Within each group, does were given either 0,1 or 2 oestrogen implants $(n=5)$. Each implant was constructed of Silastic tubing (internal diameter $3.35 \mathrm{~mm}$, external diameter $4.65 \mathrm{~mm}$ ) containing crystalline oestradiol and sealed with Silastic glue. The internal and external capsule lengths were $20 \mathrm{~mm}$ and $25 \mathrm{~mm}$, respectively and although oestrogen concentrations were not subsequently measured in these animals, oestradiol assays of plasma from castrated bucks with two identical implants from the same batch gave values of $14.7 \pm 0.95 \mathrm{pg} \mathrm{ml}^{-1}$ (S. W. Walkden-Brown, personal communication).

All animals were run together in small $(0.5-1.0$ ha) paddocks and isolated from other intact females and males on the station. During the course of the study, one nonimmunized animal with one implant died, another lost both of two oestrogen implants, and data from these animals were not considered.

\section{Immunization}

The melatonin antigen used was a melatonin-HSA conjugate made up in Freund's complete adjuvant. MelatoninHSA conjugate, $2 \mathrm{ml}$, was injected i.m. on $29 \mathrm{May}, 29$ June and 29 July, 1987. The melatonin-binding antibody titres, defined as the dilution of antiserum which bound $50 \%$ of the radiolabelled hormone available, were measured in August 1987, April 1988 and December 1989 using the method described by Foldes et al. (1983). The titres were in the range of 1:220-9000 in August 1987, 1:91000-1:500 000 in April 1988, and 1:433-18 000 in December 1989. These animals were considered to be 'highly immune' to melatonin and maintained significant antibody concentrations for more than two years. The titres recorded in the experimental animals would be expected to bind the normal nightly physiological concentrations of melatonin (Malpaux et al., 1988) for the duration of the experiment.

\section{Assay procedures}

Blood samples were collected once a week in heparinized tubes; the plasma was removed after centrifugation $(1700 \mathrm{~g}$ for $5 \mathrm{~min}$ ) and stored at $-20^{\circ} \mathrm{C}$ until assayed.

LH was measured in duplicate plasma samples using a double antibody radioimmunoassay (Campbell et al., 1991) with ovine LH antisera RI15 (Scaramuzzi et al., 1970). Standards were prepared using an LH preparation extracted and purified from goat pituitaries obtained from an abattoir by a modification of the method of Papkoff et al. (1965). Homogenized pituitaries were acidified twice, the precipitates discarded after centrifugation, the resulting supernatant neutralized and the LH present precipitated by centrifugation (at $1700 \mathrm{~g}$ for $30 \mathrm{~min}$ ). This precipitate was suspended in $0.2 \mathrm{~mol} \mathrm{~K} \mathrm{HPO}_{4} \mathrm{I}^{-1}$, heated to $55-60^{\circ} \mathrm{C}$ for $2-3 \mathrm{~min}$, and dialysed in distilled water for 4 days. Partially purified caprine LH (170.25 mg) was obtained after lyophilization. A portion
$(20 \mathrm{mg}$ ) was resuspended in phosphate, centrifuged (at $1700 \mathrm{~g}$ for $30 \mathrm{~min}$ ) and dialysed to yield $9.85 \mathrm{mg}$ of purified caprine LH.

The two purified LH preparations were assayed against an ovine LH standard (NIH-oLH-S20). The caprine LH was diluted with LH-free plasma from oestrogen-treated bucks to provide a stock solution from which standard solutions were serially diluted. The crossreactivity between the ovine LH and the ovine anti-serum was greater than for either of the caprine LH preparations, and both caprine preparations exhibited parallelism with the ovine standard curve. The caprine LH preparation was assayed to detect FSH activity in a radioreceptor assay by the method of Cheng (1975) using calf testicular membrane, PMSG and purified bovine ${ }^{125}$ I-labelled FSH. The ratio of affinity of caprine LH for the bovine FSH receptors was 625:1, indicating that the LH preparation used had low FSH activity.

This LH preparation was used to prepare standards for assays of the plasma samples. The mean assay sensitivity was $1.0 \pm 0.16 \mathrm{ng} \mathrm{ml}^{-1}$. Each assay contained five replicates of quality control standards containing 2.5, 5.0, 10.0, 20.0 and $50.0 \mathrm{ng}$ caprine $\mathrm{LH} \mathrm{ml}{ }^{-1}$. The mean intra-assay coefficients of variation for these standards were $17.37 \pm 2.56 \%$, $9.42 \pm 1.18 \%, 8.30 \pm 0.90 \%, 5.98 \pm 0.67 \%$ and $4.89 \pm 0.56 \%$, respectively, while the mean interassay coefficients of variation were $13.26 \pm 0.06 \%, 9.59 \pm 0.10 \%, 7.35 \pm 0.15 \%$, $7.29 \pm 0.28 \%$ and $3.32 \pm 0.32 \%$, respectively. The relationship between the amount of hormone added and recovered was highly significant $(P<0.001)$ and described by $y=0.546+1.005 x, R=1.00$.

\section{Statistical analyses}

The LH and livemass data for each week were grouped into monthly means for individual animals before being subjected to analyses of variance with repeated measures. Analyses of the combined data for both group I (nonimmunized) and group 2 (immunized against melatonin) showed significant third-order interactions between oestrogen treatment, month and group for LH and livemass. Further analyses were carried out within groups as follows. The livemass and LH data from group I does were subjected to an initial analysis of variance with two levels of repeated measurements (months and years), with months as replicates. As a significant year by month interaction was evident, the analysis was repeated omitting year as a factor. Similar data from group 2 were subjected to analysis of variance with only months as a repeated measure as data from only 8 months were available for the second year. The LH data from does with one or two implants only, for both groups, were subjected to further analyses of variance using the year subsets separately or combined. Because of the possibility of overestimating the statistical significance of effects where repeated measures are large, appropriate conservative estimates of error were used (Little and Hills, 1978).

The apparent difference between oestrogen implant treatments in the nonimmunized (Group 1) does was evaluated further by examining the weekly LH data in more detail. The date of commencement of a sustained change in LH concentration was determined by inspection of the raw data, and taken as the time when the mean of four subsequent sequential samples was above the mean of the previous four samples at 


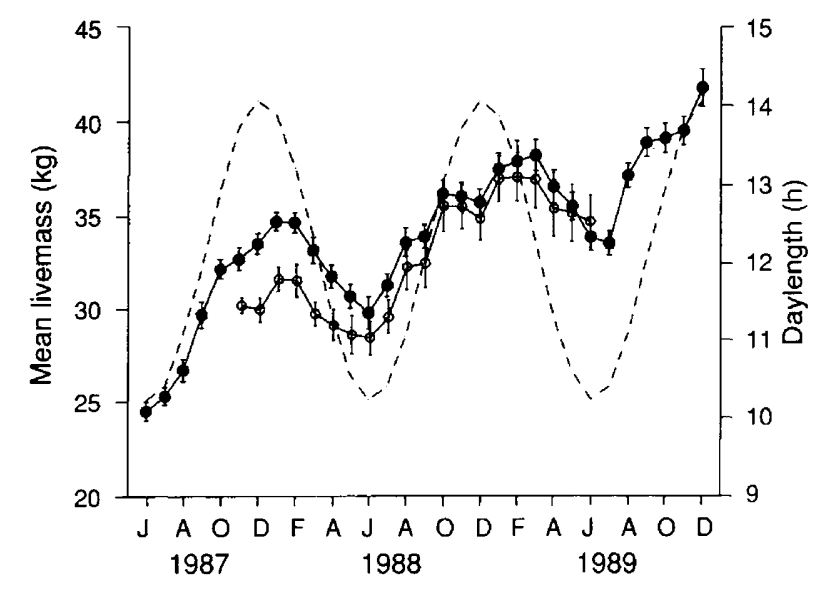

Fig. 1. Mean monthly changes in livemass of nonimmunized (•) ovariectomized does and does immunized against melatonin ( $)$. Daylength is shown as dashed line.

the commencement of the sustained rise. The end of a putative high LH secretion period was determined as the date of return to the pre-rise value. These dates were determined for the rise and fall of LH for all animals in both years, each animal contributing two complete rise and fall cycles. From these dates the following parameters were calculated: (i) time in days from summer solstice to beginning of LH rise; (ii) duration of elevated LH secretion; and (iii) time in days from winter solstice to end of the period of high $\mathrm{LH}$.

These data were subjected to analysis of variance. All statistical procedures were carried out using Systat 5.1 statistical program (Wilkinson, 1990).

\section{Results}

\section{Livemass}

The mean monthly livemasses for both nonimmunized and immunized does are shown in Fig. 1, with a summary of the variance analyses in Table 1 . There were no significant differences between the treatment groups for mean monthly livemasses of does but a significant seasonal pattern was evident (interaction between month and year, or month main effect, $P<0.01$ ) with annual maximum masses recorded in summer and the lowest masses in winter. Although the livemasses of the immunized group were lower than those of the nonimmunized does, the magnitude of the seasonal changes was similar. There was significant variation between animals for mean monthly livemass but the does increased in mass overall during the experiment attaining a final mass in excess of $40 \mathrm{~kg}$.

\section{LH concentration}

The mean monthly LH concentrations for the immunized and nonimmunized does are shown in Fig. 2 with summaries of the analyses of variance in Table 1 . The analyses revealed significant variation due to the number of implants, and an interaction between month and number of implants. Comparison of the immunized and nonimmunized does receiving oestrogen implants (the no implant data omitted) revealed a significant $(P<0.05)$ interaction between number of implants
Table 1. Summary of the analyses of variance of mean monthly livemass and LH for ovariectomized does either immunized against melatonin or not immunized, and with 0,1 or 2 oestrogen implants

\begin{tabular}{lrcc}
\hline Source of variation & $\mathrm{df}^{\mathrm{a}}$ & $\begin{array}{c}\text { Mean square } \\
\text { for LH }\end{array}$ & $\begin{array}{c}\text { Mean square } \\
\text { for livemass }\end{array}$ \\
\hline Nonimmunized does & & & \\
$\quad$ Treatment (T) & 2 & $61308.79^{*}$ & 318.64 \\
Between animals (Error 4) & 10 & $7728.58^{* *}$ & $204.10^{* *}$ \\
Month (M) & 11 & 479.78 & 190.27 \\
$\mathrm{M} \times \mathrm{T}$ & 22 & $720.31^{*}$ & 6.15 \\
Error (3) & 110 & 254.03 & 3.62 \\
Year (Y) & 1 & 4.00 & $5.07^{* *}$ \\
$\mathrm{Y} \times \mathrm{T}$ & 2 & 12.31 & 0.21 \\
Error (2) & 10 & 10.72 & 0.18 \\
$\mathrm{M} \times \mathrm{Y}$ & 11 & 74.98 & $8.07^{* *}$ \\
$\mathrm{M} \times \mathrm{T} \times \mathrm{Y}$ & 22 & 99.86 & 0.38 \\
Error (1) & 110 & 38.43 & 0.55 \\
Immunized does & & & \\
Treatment (T) & 2 & $21128.42^{* *}$ & 321.59 \\
Between animals (Error 2) & 12 & $424.171^{* *}$ & $156.21^{* *}$ \\
Month (M) & 19 & $619.31^{* *}$ & $130.67^{* *}$ \\
$\mathrm{M} \times \mathrm{T}$ & 38 & $256.31^{* *}$ & 1.95 \\
Error (1) & 228 & 15.81 & 1.77 \\
& & & \\
\hline
\end{tabular}

$* P<0.05 ; * * p<0.01$.

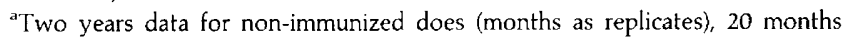
data for immunized does.

and the immunization treatment. Subsequent separate analyses of variation of the data for the implanted immunized and nonimmunized does are given in Table 2 and results for each group were as follows:

Nonimmunized does. In ovariectomized does without oestrogen implants, LH concentrations initially fell in the first month before increasing steadily for the next 7 months (Fig. 2). The LH concentrations then appeared to reach a plateau and were relatively constant for the remainder of the experiment in three of the five does. In the other two does, LH concentrations rose sharply in August 1988 and remained high until February 1989, then dropped back to the plateau levels.

In both years during the normal anoestrous period (September-December) the mean monthly LH concentration was low in does with oestrogen implants. The LH concentration appeared to rise in January or February in the does with two oestrogen implants, but not until May in those with one oestrogen implant. Irrespective of the number of oestrogen implants, LH concentrations fell at the beginning of the anoestrous period in September (Fig. 2).

Considerable individual variation was evident (Table 2 ) and both combined or separate analyses of the data for each year revealed significant variation due to the month of observation $(P<0.01)$ and a significant interaction between the month of observation and the number of implants $(P<0.052)$. This interaction was examined in more detail by analysis of the weekly LH concentrations.

The mean weekly LH concentrations for the four animals in each implant group from January to September of each year are 

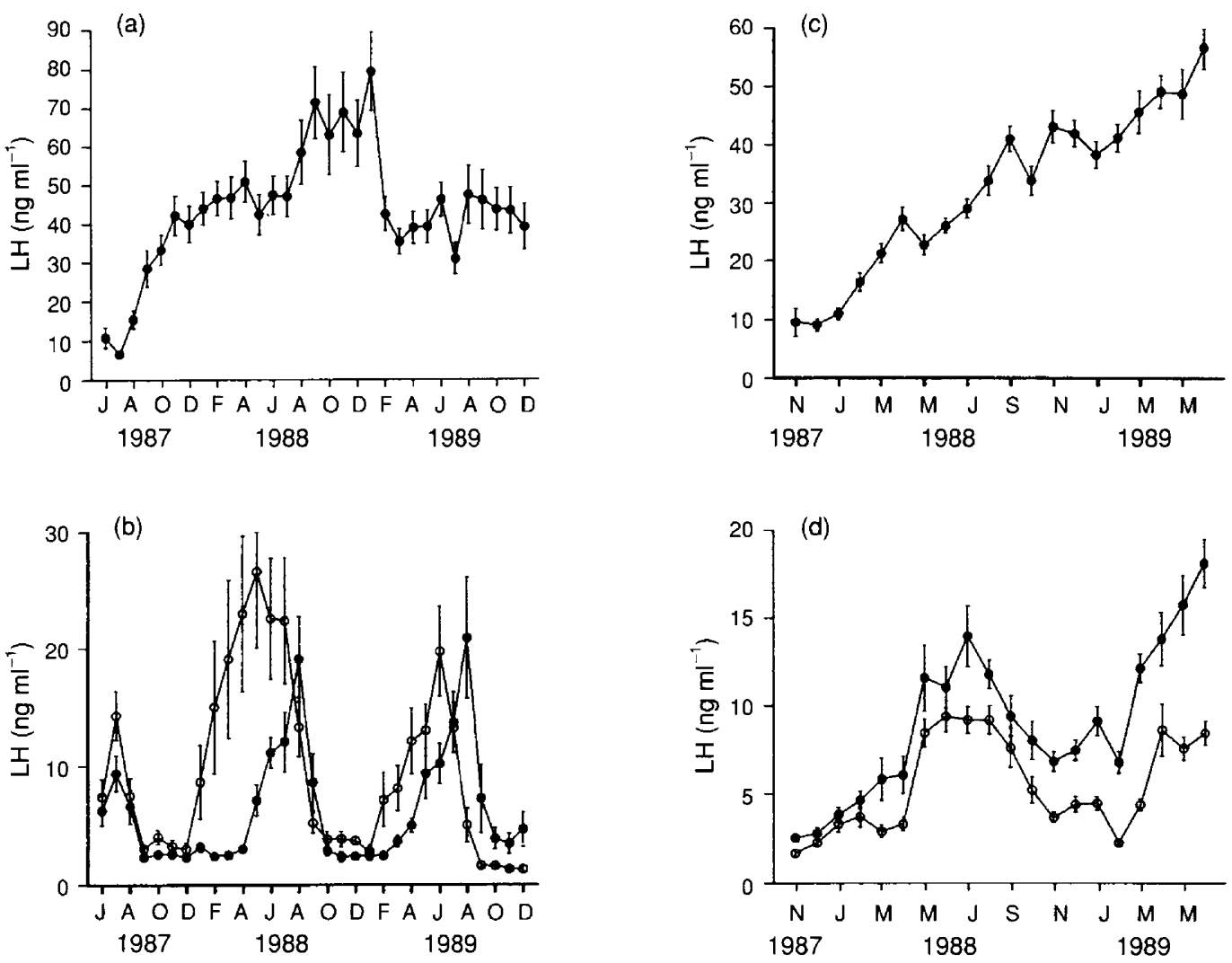

Fig. 2. Seasonal changes in mean monthly LH concentration in ovariectomized does. Figures on the left are for nonimmunized does with (a) no implant or (b) one ( $\bullet$ ) or two ( ) oestrogen implants. Corresponding data for does immunized against melatonin are shown on the right $(c, d)$. Note that the $y$ axes have different scales.

shown in Fig. 3; as the data showed heterogeneous variation it has been transformed to logarithms. For the does receiving two oestrogen implants, the mean weekly LH concentration was more variable than for those receiving only one implant, but the rise in LH concentration was clearly in advance of that of does receiving one implant. The mean interval from the summer solstice to the commencement of the rise, the duration of the rise and the interval from winter solstice to the end of the rise are shown in Table 3. The analysis of variance of these data showed a significant effect of the number of implants on the commencement of the rise, with those does receiving two implants commencing, on average, 58 days earlier than those with one implant (Table 3). The average date of commencement of the LH rise was 28 April for does with one implant, and 29 February for those with two implants.

There was considerable variation between animals in the group that received two implants particularly in the first year (Fig. 3); two animals in one or other year showed either a very early rise ( 1 January) or a late rise (22 April) in weekly $\mathrm{LH}$ concentration. However, of the eight secretory periods observed for the two implant does, six began at the earlier date.

The duration of the high LH secretory period was significantly $(P<0.05)$ longer in does with two implants than in those with one, with an average extension of 51 days (Table 3).

There were no significant differences between does with one or two implants in the time after the winter solstice when the high LH secretory pattern ended. However, the high LH secretory periods ended significantly $(P<0.05)$ earlier in the second year; the mean dates of cessation were 6 September (year 1) and 18 August (year 2), a difference of about 3 weeks.

Does immunized against melatonin. The mean monthly LH concentrations for the animals immunized against melatonin are shown in Fig. 2, with the summary of the analyses of variance in Tables 1 and 2. Ovariectomized immunized does without oestrogen implants showed a steady increase in LH concentration during the 20 months of observation without a discern ible plateau. When only animals with implants were considered, both separate and combined analyses of the data for each year (Table 2) showed significant variation due to the month of the year $(P<0.01)$ and the month by treatment interaction $(P<0.052)$. Immunized does with oestrogen implants showed a much smaller seasonal rise in LH concentration than did the nonimmunized animals. In contrast to the nonimmunized does, those animals with two implants of oestrogen showed significantly $(P<0.01)$ lower LH concentrations than those with one implant. There was no evidence of an early rise in $\mathrm{LH}$ concentration due to the number of implants.

\section{Discussion}

The seasonal pattern of live mass changes observed in the study reported here is similar to other studies of Australian 
Table 2. Summary of the analyses of variance (mean squares) for mean monthly LH in nonimmunized and immunized ovariectomized does with I or 2 oestrogen implants

\begin{tabular}{|c|c|c|c|c|c|c|}
\hline Source of variation & $\mathrm{df}$ & \multicolumn{2}{|c|}{ Year I } & \multicolumn{2}{|c|}{ Year 2} & Combined year 1 and year 2 \\
\hline \multicolumn{7}{|l|}{ Nonimmunized does ${ }^{\mathrm{a}}$} \\
\hline Number of implants (T) & 1 & 1348.47 & & 4.19 & & 751.52 \\
\hline Between animals (Error I) & 6 & 1329.73 & & 221.01 & & 1202.5 \\
\hline Month (M) & 11 & $268.21^{* *}$ & & $179.18^{* *}$ & & $410.41^{* *}$ \\
\hline $\mathrm{M} \times \mathrm{T}$ & 11 & $156.28^{*}$ & & $88.94 *$ & & $275.98^{*}$ \\
\hline Error (2) & 66 & 89.32 & & 46.32 & & 147.69 \\
\hline Year $(Y)$ & 1 & & & & & 16.75 \\
\hline $\mathrm{Y} \times \mathrm{T}$ & $I$ & & & & & 2.72 \\
\hline Error (3) & 6 & & & & & 9.94 \\
\hline$M \times Y$ & 11 & & & & & $71.5^{* *}$ \\
\hline$M \times Y \times T$ & 11 & & & & & 23.6 \\
\hline Error (4) & 66 & & & & & 18.6 \\
\hline Immunized does ${ }^{b}$ & & & $d f$ & & $\mathrm{df}$ & \\
\hline Number of implants (T) & 1 & $133.04^{* *}$ & 1 & $666.92 * *$ & 1 & $638.44^{* *}$ \\
\hline Between animals (Error 2) & 8 & $25.64^{* *}$ & 8 & 9.23 & 8 & $21.86^{* *}$ \\
\hline Month (M) & 11 & $117.27 * *$ & 7 & $108.46^{*}$ & 19 & $116.00^{* *}$ \\
\hline $\mathrm{M} \times \mathrm{T}$ & 11 & 4.14 & 7 & 15.00 & 19 & $16.42^{*}$ \\
\hline Error (1) & 88 & 7.23 & 56 & 7.71 & 152 & 7.71 \\
\hline
\end{tabular}

$* P<0.05 ; * P<0.01$.

a Data for two years with months as replicates in the combined analysis.

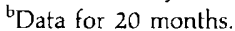
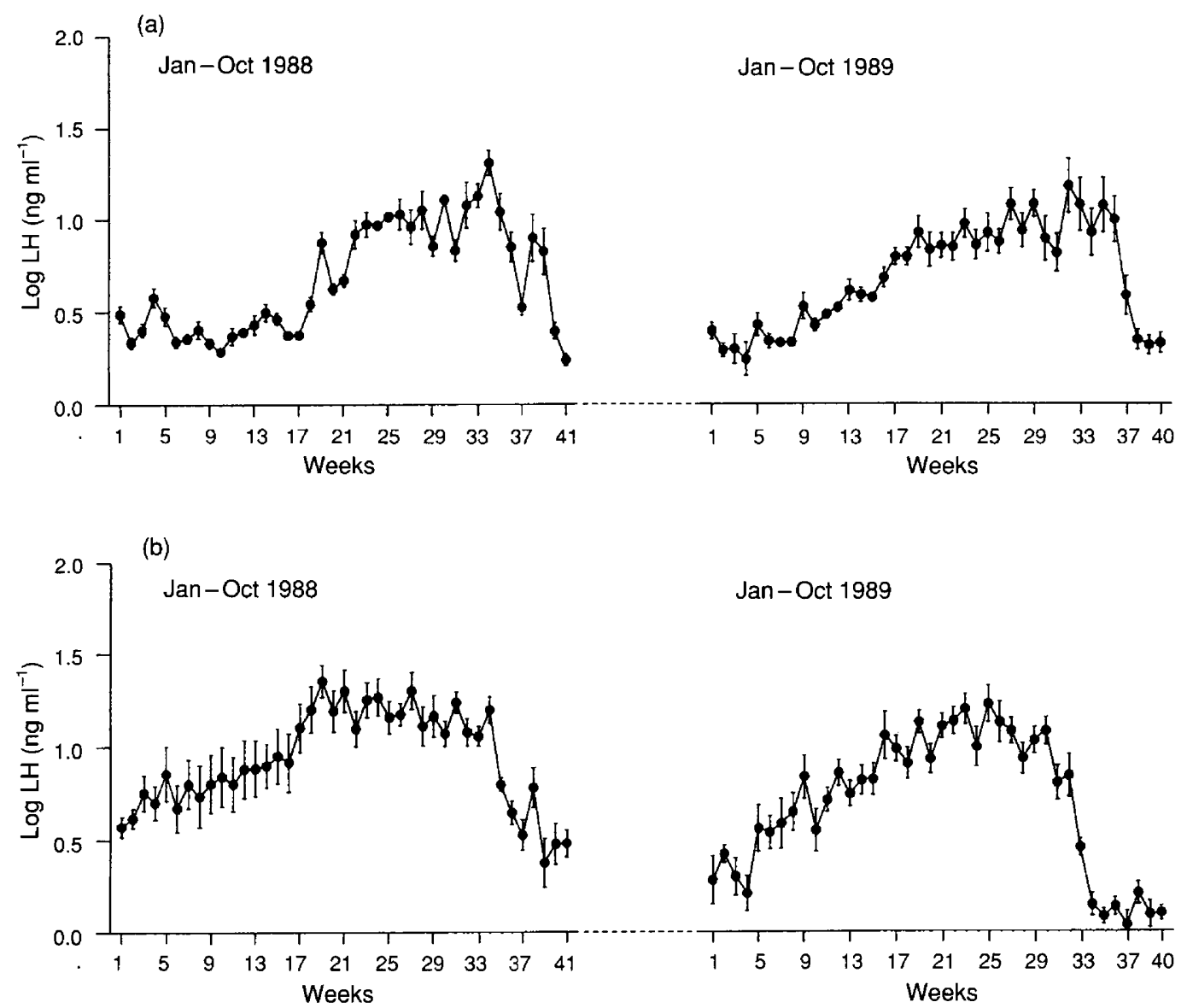

Fig. 3. Mean weekly LH ( $\log _{10}$ transform) for ovariectomized does with (a) one or (b) two oestrogen implants between January and October for two consecutive years. 
Table 3. Commencement, duration and end of the seasonal rise in LH secretion in nonimmunized ovariectomized does treated with either 1 or 2 implants of oestradiol (data are means and standard deviations) together with a summary of the analyses of variance

\begin{tabular}{|c|c|c|c|c|}
\hline \multirow[b]{3}{*}{ Parameter } & \multicolumn{4}{|c|}{ Treatment } \\
\hline & \multicolumn{2}{|c|}{$\begin{array}{c}\text { Ovariectomized } \\
+1 \text { oestrogen implant }\end{array}$} & \multicolumn{2}{|c|}{$\begin{array}{c}\text { Ovariectomized } \\
+2 \text { oestrogen implants }\end{array}$} \\
\hline & Year 1 & Year 2 & Year 1 & Year 2 \\
\hline Period from summer solstice to start of LH rise (days) & $132.5 \quad(4.04)$ & $124.5 \quad(4.04)$ & $73.3(46.3)$ & $66.8(29.9)$ \\
\hline Duration of LH rise (days) & $126 \quad(20.6)$ & $123.3(23.8)$ & $183.5(54.8)$ & $167.5(36.8)$ \\
\hline
\end{tabular}

Summary of the analyses of variance

\begin{tabular}{lcccc}
\hline Source of variation & $\mathrm{df}$ & $\begin{array}{c}\text { Days from summer } \\
\text { solstice to LH rise }\end{array}$ & $\begin{array}{c}\text { Duration of } \\
\text { LH rise }\end{array}$ & $\begin{array}{c}\text { Days from winter solstice } \\
\text { to end of LH rise }\end{array}$ \\
\hline Number of implants $(\mathrm{T})$ & 1 & $13689^{* *}$ & $10353.07^{* *}$ & 150.07 \\
Year $(\mathrm{Y})$ & 1 & 210.25 & 351.57 & $1387.57^{*}$ \\
$\mathrm{~T} \times \mathrm{Y}$ & 1 & 2.25 & 175.55 & 248.06 \\
Error & 12 & 768.46 & 1337.23 & 282.77 \\
\hline
\end{tabular}

${ }^{*} P<0.05 ; * * P<0.01$.

goats (Ash, 1986; Klören, 1991; Walkden-Brown et al., 1994), and to ruminants in general (Forbes, 1982; Kay, 1985). This pattern of growth is considered to be due to a circannual cycle in voluntary feed intake that is photoresponsive and may be secondary to a primary growth cycle. The magnitude of the observed loss of mass in autumn ( $14.3 \%$ for nonimmunized does, $12.5 \%$ for immunized does) is similar to that observed by Walkden-Brown (1991) for grazing bucks at the same location (14.8-19.5\% loss in mass). Walkden-Brown (1991) also provided evidence for an influence of age; the magnitude of the livemass effect changed from a growth stasis in the first year of life to an increasing loss of mass as animals grew older. The exact nature of the effect is unknown.

Annual growth rhythms have been shown to be photoinducible in a number of domestic species (sheep: Forbes et al., 1979; Kay and Suttie, 1980; Soay rams: Suttie et al., 1984; cattle: Peters et al., 1980) including Australian goats (Ash, 1986). However, our results do not show any significant difference between the immunized and nonimmunized does in the seasonal livemass pattern. The immunized does were unlikely to have been able to transduce photoperiodic signals as two other studies at this centre have shown that similar immunization treatment interferes with the expression of the photoperiodically controlled fleece growth rhythm (Sutherland et al., 1990; Foldes et al., 1992). The immunized does would be expected to behave as pinealectomized animals (Martenz, 1980), unable to transduce photoperiodic changes, and it is known that photoinducible rhythms can persist for up to three years following pinealectomy or superior cervical ganglionectomy (Bittman, 1985; Argo, 1985 cited by Kay, 1985). This persistence is considered evidence of an endogenous rhythm (Bittman, 1985) but the existence of an endogenous rhythm is by no means established. As all goats were fed supplements in the study reported here, it is concluded that the observed seasonal changes in livemass in the does immunized against melatonin are due to persistence of a previously entrained rhythm, rather than merely reflecting seasonal pasture changes.

LH concentrations showed a distinct seasonal pattern in the presence of circulating oestrogen with significant differences due to the number of implants. It was not possible to measure the concentration of circulating oestrogen resulting from the implants, but two similar sized implants in castrated bucks at the same location resulted in concentrations of $14.7 \pm 0.95$ pg $\mathrm{ml}^{-1}$ (S. W. Walkden-Brown, personal communication). Slightly higher concentrations would be expected in the does studied because of sex differences in livemass, and does with one implant would be expected to have lower circulating concentrations of oestrogen. These estimates are comparable to the results of Chemineau et al. (1982) who found oestradiol concentrations of $10 \mathrm{pg} \mathrm{ml}^{-1}$ in seasonally anoestrous goats. Karsch et al. (1980, 1983) showed that sheep with two implants of similar size had circulating oestrogen concentrations three times higher than those with one implant, and we consider that the two treatments imposed on the does in the present study would have resulted in a similar difference in circulating oestrogen.

The seasonal pattern of $\mathrm{LH}$ concentration varied with the number of implants, and by inference, with the concentration of circulating oestrogen; the period of high $\mathrm{LH}$ concentration in does with one implant corresponds to the period of spontaneous ovulatory activity (Restall, 1992), but it began much earlier and lasted much longer in does with two implants. This earlier rise in LH concentrations in does with two implants corresponds to the responsive period of the seasonal rhythm in which anovulatory animals can be induced to ovulate (Chemineau, 1983; Restall, 1992). The LH pattern in does with one implant is similar to that described for sheep and attributed to changes in hypothalamic sensitivity to negative feedback of oestrogen (Legan and Karsch, 1979; Karsch et al., 1984). However, the mechanisms underlying the anovulatory 
responsive period and the following relatively short period of spontaneous ovulation in our goats are not known.

Sutherland (1987) studied seasonal changes in negative oestrogen feedback in Angora $\times$ Australian goats, and concluded that the control was the same as in sheep, that is primarily a differential negative feedback effect of oestradiol. His experiment was conducted in April during the responsive anovulatory period, and used a single low dose of oestrogen analogous to the one implant treatment in the present study, and gave a similar result. This putative seasonal change in sensitivity to negative oestrogen feedback does not explain the earlier rise in LH observed in does with two implants, as the higher oestrogen concentration would be expected to suppress, not release, $\mathrm{LH}$.

A possible explanation for the observed differential LH pattern in does with one or two implants is that a positive oestrogen feedback system is present all year round but with varying sensitivity. In the experiment reported here $\mathrm{LH}$ was low in does with one implant in the anovulatory responsive period (Feb-May) due to sensitivity of the negative oestrogen feedback. The higher $\mathrm{LH}$ concentrations in does with two implants cannot be due to tonic LH release, as this is suppressed during the anovulatory responsive period, but may be a result of a weak positive oestrogen feedback stimulus. In the following period of spontaneous ovulation (May-July), a positive feedback effect may be masked by the increased tonic LH secretion associated with the change in negative oestrogen feedback. Such a system of differential change in positive and negative oestrogen feedback could control the observed periods of spontaneous ovulation, and the responsive and nonresponsive periods of anovulation in this species (Restall, 1992).

Such apparent 'positive' oestrogen feedback effects may be a general phenomenon. A chronic positive feedback effect of oestradiol in ovariectomized heifers in all seasons has been reported (Critser et al., 1983) as well as a seasonal variation in LH concentrations. The treatment of ovariectomized cows with oestradiol increases both mean concentration and amplitude of LH pulses throughout the year (Day et al., 1986; Stumpf et al., 1988); the magnitude of the response depends on the season. There is some evidence that low concentrations of oestradiol administered to ovariectomized cows decrease pulse frequency while enhancing amplitude (Kinder et al., 1991). Similarly, oestradiol increases mean LH concentrations in ovariectomized mares, with a greater enhancement in the breeding season (Garcia and Ginther, 1978). Reports of a chronic positive feedback effect of oestradiol on $\mathrm{LH}$ resulting in increases in pulse amplitude but not frequency, for both a seasonal and nonseasonal breeding species, contrast with the dramatic seasonally dependent inhibitory effect of oestradiol in ovariectomized ewes (Legan et al., 1977), in which frequency but not amplitude, of pulses is suppressed (Goodman and Karsch, 1980). Chemineau et al. (1988b) found that LH pulse frequency increases gradually by $65 \%$ in French Saanen goats as the breeding season approaches which was interpreted as an easing of the negative oestrogen feedback inhibition. Mori et al. (1987) report that in ovariectomized Shiba goats the hypothalamic-pituitary axis becomes hypersensitive to both the positive and negative feedback effect of oestradiol under long day conditions, indicative of independent mechanisms.
These reports, together with the results of the study reported here, suggest that there is a general positive oestrogen feedback effect that is expressed differently in different species under similar circumstances. An enhancement of the positive effect during the sensitive anovulatory phase in our goats may underpin the marked responses to environmental stimuli, such as the introduction of males, at that time of the year (Walkden-Brown et al., 1993).

Does immunized against melatonin showed a very different pattern of LH secretion from that of the nonimmunized animals. While the seasonal change in LH secretion corresponding to the period of spontaneous ovulations was still evident, there was no effect of the number of implants, and by inference the dose of oestrogen. In fact the higher dose appeared to be more suppressive of $\mathrm{LH}$ secretion than did the lower dose, as might be expected if only the negative feedback mechanism was operative. While the effect of immunization on the biological activity of circulating melatonin has not been demonstrated, studies involving immunization against melatonin are in agreement that immunized animals are similar to pinealectomized animals and this is consistent with the interpretation that immunization has blocked the biological activity of melatonin (Martenz, 1980). If the immunization of our animals effectively removed their ability to transduce the normal light signal, then the absence of the putative positive feedback mechanism evident in the nonimmunized does receiving the higher oestrogen dose implies that it is under photoperiodic control, but is not entrained. The persistence of the negative feedback rhythm without photoperiodic change suggests that it is either an endogenous or entrained rhythm. In sheep that have been pinealectomized or have undergone superior ganglionectomy, negative feedback and behavioural rhythms may persist for long periods, although synchrony and seasonal phasing may be lost quickly (Karsch et al., 1984; Bittman, 1985; Karsch and Woodfill, 1990).

The results reported here are consistent with other studies of goats (Sutherland, 1987; Chemineau et al., 1988a, b) and suggest possible mechanisms underlying seasonal reproductive rhythms. We propose that a negative oestrogen feedback system prevents the expression of ovulatory activity for most of the year, and that a positive oestrogen feedback mechanism, indicated by a rise in circulating $\mathrm{LH}$ concentrations, renders the animal responsive to other stimuli for a varying period before the resumption of spontaneous ovulatory activity. This putative positive feedback mechanism may be dependent on a photoperiodic signal for activation, but further research is warranted as it may underlie the ability of goats to respond opportunistically to short-term changes in their physical environment.

The experiments described here were approved by the Animal Health and Welfare Committee of NSW Agriculture. A preliminary report of this work was presented at the 21st Annual Conference of the Australian Society for Reproductive Biology, Monash University, 25-27 September 1989. The study was supported by the Rural Credits Development Fund (Project NSWDA/87/47). The authors thank J. F. Murray for carrying out the radioreceptor assay, and R. M. Hoskinson for determination of antibody titres. They also thank J. A. Downing for assistance with radioimmunoassay, and $W$. A. Taylor, R. B. Lewis, G. Allen, K. Fredrickson, the late D. Wallace for assistance with animal handling and management. 


\section{References}

Arendt J (1986) Role of the pineal gland and melatonin in seasonal reproductive function in mammals Oxford Reviews of Reproductive Biology 8 $266-320$

Ash AJ (1986) A Study of Body and Cashmere Growth in Weaning Goats PhD thesis, University of Queensland

Bittman EL (1985) The role of rhythms in the response to melatonin. In Photoperiodism, Melatonin and the Pineal. ClBA Foundation symposium no. $117 \mathrm{pp} \mathrm{149-163.} \mathrm{Eds} \mathrm{D} \mathrm{Evered} \mathrm{and} \mathrm{J} \mathrm{Clark.} \mathrm{Pitman,} \mathrm{London}$

Campbell BK, Scaramuzzi RJ, Evans G and Downing JA (1991) Increased ovulation rate in androstenedione-immune ewes is not due to elevated plasma concentrations of FSH Journal of Reproduction and Fertility 91 655-666

Chemineau P (1983) Effect on oestrus and ovulation of exposing Creole goats to the male at three times of the year Journal of Reproduction and Fertility 67 $65-72$

Chemineau P, Gauthier D, Poirier JC and Saumande J (1982) Plasma levels of LH, FSH, prolactin, oestradiol and progesterone during natural and induced oestrus in the dairy goat Theriogenology 17 313-323

Chemineau P, Pelletier J, Guérin Y, Colas G, Ravault JP, Touré G, Almeida G, Thimonier J and Ortavant $\mathbf{R}$ (1988a) Photoperiodic and melatonin treatments for the control of seasonal reproduction in sheep and goats Reproduction and Nutrition Dévelopment 28 409-422

Chemineau P, Martin GB, Saumande J and Normant E (1988b) Seasonal and hormonal control of pulsatile LH secretion in the dairy goat (Capra hircus) Journal of Reproduction and Fertility $\mathbf{8 3} 91-98$

Cheng KW (1975) A radioreceptor assay for follicle stimulating hormone Journal of Clinical Endocrinology and Metabolism 41 581-589

Critser JK, Miller KF, Gunsett FC and Ginther OJ (1983) Seasonal LH profile in ovariectomised cattle Theriogenology 19 181-191

Day ML, Imakawa K, Pennel PL, Zalesky DD, Clutter AC, Kittok RJ and Kinder JE (1986) Influence of season and oestradiol on secretion of LH in ovariectomised cows Biology of Reproduction 62 1641-1648

Foldes A, Hoskinson RM, Scaramuzzi RJ, Hinks NT and Maxwell CA (1983) Modification of sheep pineal beta receptors by some gonadal steroids, but not by melatonin Neuroendocrinology 37 378-386

Foldes A, Hoskinson RM, Baker P, McDonald BJ, Maxwell CA and Restall BJ (1992) Effect of immunisation against melatonin on seasonal fleece growth in feral goats journal of Pineal Research 13 85-94

Forbes JM (1982) Effects of lighting pattern on growth, lactation and food intake of sheep, cattle and deer Livestock Production Science 9 361-374

Forbes JM, El Shabat AA, Jones R, Duncan JGS and Boaz TG (1979) The effect of daylength on the growth of lambs. 1. Comparisons of sex, level of feeding, shearing and breed of sire Animal Production 29 33-42

Garcia MO and Ginther OJ (1978) Regulation of plasma LH by oestradiol and progesterone in ovariectomized mares Biology of Reproduction 19 $447-452$

Goodman RL and Karsch FJ (1980) Pulsatile secretion of luteinizing hormone: differential suppression by ovarian steroids Endocrinology 107 1286-1290

Hecker FJ (1974) Experimental Surgery in Small Ruminants Butterworths, London

Karsch FJ and Woodfill CJI (1990) Neuroendocrinology of seasonal breeding: mode of action of melatonin. In Neuroendocrine Regulation of Reproduction pp 9-17 Eds SSC Yen and WW Vale. Serono Symposia, Norwell, MA

Karsch FJ, Legan SJ, Ryan KD and Foster DL (1980) Importance of oestradiol and progesterone in regulating LH secretion and estrous behaviour during the sheep estrous cycle Biology of Reproduction 23 404-413

Karsch FJ, Foster DL, Bittman EL and Goodman RL (1983) A role for oestradiol in enhancing luteinizing hormone pulse frequency during the follicular phase of the oestrous cycle of sheep Endocrinology 113 1333-1339

Karsch FJ, Bittman EL, Foster DL, Goodman RL, Legan SJ and Robinson JE (1984) Neuroendocrine basis of seasonal reproduction Recent Progress in Hormone Research 40 185-232

Kay RNB (1985) Seasonal variation of appetite in ruminants. In Recent Advances in Animal Nutrition pp 199-211. Eds W Haresign and DJA Cole. Butterworth, London

Kay RNB and Suttie JM (1980) Relationship of seasonal cycles of food intake and sexual activity in Soay rams Journal of Physiology 310 34-35 (Abstract)

Kinder JE, Garcia-Winder M, Imakawa K, Day ML, Zalesky DD, D'Occhio ML, Stumpf TT, Kittok RJ and Schanbacher BD (1991) Circulating concentrations of oestradiol influence pattern of $\mathrm{LH}$ in circulation of cows Domestic Animal Endocrinology 8 463-469
Klören WRL (1991) The Physiological and Environmental Factors Affecting Cashmere Growth in Australian Cashmere Goats PhD Thesis, University of Queensland

Legan SI and Karsch FJ (1979) Neuroendocrine regulation of the estrous cycle and seasonal breeding in the ewe Biology of Reproduction 20 74-85

Legan SJ, Karsch FJ and Foster DL (1977) The endocrine control of seasonal reproductive function in the ewe: a marked change in the response to the negative feedback action of oestradiol on luteinizing hormone secretion Endocrinology $101818-824$

Little TM and Hills FJ (1978) Agricultural Experimentation: Design and Analysis John Wiley and Sons, New York

Maeda KI, Mori Y and Kano Y (1988) Involvement of melatonin in the seasonal changes of the gonadal function and prolactin secretion in female goats Reproduction and Nutrition Dévelopment 28 487-497

Malpaux B, Moenter SM, Wayne NL, Woodfill CJI and Karsch FJ (1988) Reproductive refractoriness of the ewe to inhibitory photoperiod is not caused by alteration of the circadian secretion of melatonin Neuroendocrinology $\mathbf{4 8}$ 264-270

Martenz ND (1980) The biological effects of immunisation against steroids in female mammals Oxford Reviews of Reproductive Biology 2 232-262

Martin GB and Thomas GB (1990) Roles of communication between the hypothalamus, pituitary gland and ovary in the breeding activity of ewes. In Reproductive Physiology of Merino Sheep: Concepts and Consequences pp 23-40 Eds CM Oldham, GB Martin and IW Purvis. School of Agriculture, University of Western Australia, Perth

Mori Y, Tanaka M, Maeda K, Hoshino K and Kano Y (1987) Photoperiodic modification of negative and positive feedback effects of oestradiol on LH secretion in ovariectomized goats Journal of Reproduction and Fertility $\mathbf{8 0}$ 523-529

Papkoff H, Gospodarowicz D, Candiotti A and Choh Hao Li (1965) Preparation of ovine interstitial cell-stimulating hormone in high yield Archives of Biochemistry and Biophysics $111431-438$

Pelletier J and Ortavant R (1975) Photoperiodic control of LH release in the ram Acta Endocrinologica $\mathbf{7 8} 442-450$

Peters RR, Chapin LT, Emery RS and Tucker HA (1980) Growth and hormonal response of heifers to various photoperiods Journal of Animal Science $\mathbf{5 1}$ 1148-1153

Restall B] (1988) Artificial insemination of Australian goats stimulated by the 'buck effect' Proceedings of the Australian Society of Animal Production 17 302-305

Restall BJ (1992) Seasonal variation in reproductive activity in Australian goats Animal Reproduction Science 27 305-318

Restall BJ and Pattie WA (1989) The inheritance of cashmere in Australian goats 1. Characteristics of the base population and the effects of environmental factors Livestock Production Science 21 157-172

Scaramuzzi RJ, Caldwell BV and Moor RM (1970) Radioimmunoassay of LH and oestrogen during the estrous cycle of the ewe Biology of Reproduction 3 110-119

Stumpf TT, Day ML, Wolfe PL, Wolfe MW, Clutter AC, Kittok RJ and Kinder JE (1988) Feedback of 17-oestradiol on secretion of luteinizing hormone during different seasons of the year Journal of Animal Science 66 447-451

Sutherland SRD (1987) Effects of oestradiol and progesterone on LH secretion during anoestrus and the breeding season in ovariectomized Angora-cross does Proceedings 4th AAAP Animal Science Congress, Hamilton p 230 (Abstract)

Sutherland SRD, Henniawati, Restall BJ and Hoskinson RM (1990) Cashmere growth in Australian goat does immunised against melatonin Proceedings of the Australian Society of Animal Production 19 380-383

Suttie JM, Kay RNB and Goodall ED (1984) The influence of superior cervical sympathetic ganglionectomy on cycles of appetite and growth in Soay rams on a six-month photoperiod Livestock Production Science 11 529-534

Walkden-Brown SW (1991) Environmental and Social Influences on Reproduction in Australian Cashmere Goats PhD Thesis, University of Queensland

Walkden-Brown SW, Restall BJ and Henniawati (1993) The male effect in the Australian cashmere goat. 3. Enhancement with buck nutrition and use of oestrous females Animal Reproduction Science 32 69-84

Walkden-Brown SW, Norton BW and Restall BJ (1994) Seasonal variation in voluntary feed intake and growth in cashmere bucks fed ad libitum diets of low or high quality Australian Journal of Agricultural Research 45 355-366 Wilkinson L (1990) SYSTAT: The System for Statistics SYSTAT Inc. Evanson, IL 